\title{
Adaptive fuzzy sliding mode based MPPT controller for a photovoltaic water pumping system
}

Sabah Miqoi, Abdelghani El Ougli, Belkassem Tidhaf

National School of Applied Sciences, Mohammed First University, Morocco

\begin{tabular}{|c|c|}
\hline Article Info & ABSTRACT \\
\hline Article history: & The applications of photovoltaic energy are steadily increasing. However, \\
\hline Received Sep 6, 2018 & $\begin{array}{l}\text { the output power of a photovoltaic system is influenced by the } \\
\text { meteorological conditions (temperature and irradiation), which can affect the }\end{array}$ \\
\hline Revised Oct 27, 2018 & production and efficiency of the photovoltaic panel energy. So to ensure that \\
\hline Accepted Dec 4, 2018 & $\begin{array}{l}\text { the photovoltaic panel produces its maximum power possible at any time and } \\
\text { regardless of the external conditions, we use the equipment called MPPT }\end{array}$ \\
\hline Keywords: & $\begin{array}{l}\text { (maximum power point tracker). Sliding mode control is recognized by its } \\
\text { stability and robustness and widely used in non-linear systems but represents }\end{array}$ \\
\hline Adaptive control & a disadvantage because of the chattering phenomena. So in order to \\
\hline AFSMC & $\begin{array}{l}\text { overcome this problem and improve this control, we opted to add to it the } \\
\text { adaptive fuzzy control which will adapt the switching gain. This controller is }\end{array}$ \\
\hline DC motor & named AFSMC (adaptive fuzzy sliding mode control) and will be compared \\
\hline DC-DC boost converter & the sliding mode controller SMC in order to see the difference and to the \\
\hline Fuzzy control & $\mathrm{P} \& \mathrm{O}$ (perturb \& observe) method to validate this controller. Our system \\
\hline MPPT & consists of a photovoltaic panel a DC-DC boost converter and a centrifugal \\
\hline $\mathrm{P} \& \mathrm{O}$ & pump with a DC motor. All simulations are carried out under \\
\hline Photovoltaic PV & MATLAB/SIMULINK and the extracted results show the efficiency of the \\
\hline SMC & AFSMC controller and confirm that the new methods have improved energy \\
\hline Water pump & efficiency and production. \\
\hline
\end{tabular}

Copyright (C) 2019 Institute of Advanced Engineering and Science. All rights reserved.

\section{Corresponding Author:}

Sabah Miqoi,

Laboratory of Embedded Electronic Systems and Renewable Energy,

National School of Applied Sciences, Mohammed First University,

BP 71760000 Oujda Maroc ‘BV Mohamed VI BP 717, Oujda 60000, Morocco.

Email: sabah.miq@gmail.com

\section{INTRODUCTION}

The application and development of photovoltaic energy is increasing all over the world. Photovoltaic pumping is one of the promising applications for the use of photovoltaic energy, particularly in rural areas that have a substantial amount of insolation and have no access to an electric grid [1]. Then our system consists of a photovoltaic panel that supplies energy to the water pump via a DC / DC converter and a DC motor. Among the benefits of using a photovoltaic source is that it is free and sustainable fuel source; there light-weight, although PV systems may expand over large areas; noise free operation due to the absence of large rotating machinery; the possibility of application close to the point of use; ease of installation; predictable availability in certain geographical regions; and systems require relatively little regular maintenance.

In spite of all these advantages, PV system is known for the nonlinear current-voltage and powervoltage characteristics which depends on the variations in temperature and solar irradiation, therefore the photovoltaic system does not produce its maximum energy all the time which leads to low efficiency. There is a unique point on the P-V (Power-Voltage) characteristic, known as the MPP (maximum power point) where the photovoltaic cell produces its maximum power. Therefore, the PV systems require an equipment to track the MPP at all time, regardless of the temperature and solar irradiation. A significant number of MPPT 
control systems have been developed for years, starting with simple techniques such as voltage or current and Hill climbing, Incremental inductance and Perturb and Observe; those are the conventional control techniques [2]. On the other hand, unconventional techniques such as fuzzy logic, artificial neural network and sliding mode control, which can provide more stability and robustness, have been widely used and developed.

The sliding mode controller is much known for its robustness and stability and is wildly used in non linear systems and especially on aircraft control [3]. However this controller represents a disadvantage called the chattering phenomena resulting from the high oscillations around the sliding surface. To overcome this disadvantage we have tried to develop the sliding mode controller by replacing the switching gain by an adaptive fuzzy gain. This method is called Adaptive Fuzzy Sliding Mode Control AFSMC.

In this paper, a photovoltaic water pumping system, was studied and the mathematical modelling of its equipments is represented [4]. The different MPPT techniques used have also been studied and analyzed and also compared. The system has been tested and assessed using MATLAB/Simulink.

\section{PV WATER PUMPING SYSTEM DESIGN:}

Our system consists of a photovoltaic panel a DC-DC boost converter and a centrifugal pump with a DC motor. Figure 1 shows the equivalent circuit of the system in all.

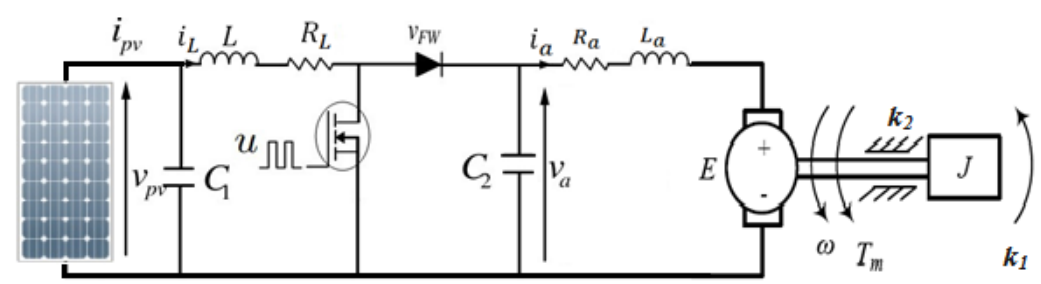

Figure 1. Equivalent circuit of the system

The system's average model is given in the (1):

$$
\left\{\begin{array}{l}
\frac{d i_{L}}{d t}=\frac{V_{p v}}{L}-\frac{R_{L}}{L_{L}} i_{L}+\frac{-R_{m} i_{L}+V_{F W}+V_{a}}{L} u-\frac{V_{F W}}{L}-\frac{V_{a}}{L} \\
\frac{d V_{p v}}{d t}=\frac{i_{p v}}{C_{1}}-\frac{i_{L}}{C_{1}} \\
\frac{d i_{a}}{d t}=\frac{-R_{a}}{L_{a}} i_{a}+\frac{V_{a}}{L_{a}}-\frac{k}{L_{a}} \omega \\
\frac{d V_{a}}{d t}=-\frac{i_{a}}{C_{2}}+\frac{i_{L}}{C_{2}}-\frac{i_{L}}{C_{2}} u \\
\frac{d \omega}{d t}=\frac{k}{j} i_{a}-\frac{k_{2}}{j} \omega-\frac{k_{1}}{j}
\end{array}\right\}
$$

Where $\mathrm{u}$ is the control input. $\mathrm{L}, \mathrm{RL}$ and $\mathrm{i}_{\mathrm{L}}$ are the self-inductance, resistance and current. $\mathrm{R}_{\mathrm{m}}$ is the resistance characterizing IGBT lost. $\mathrm{C}_{1}$ and $\mathrm{C}_{2}$ are the input and the output capacitance respectively. $V_{\mathrm{FW}}$ is the diode forward voltage. The state representation of the system is written as:

$$
\frac{\mathrm{d}}{\mathrm{dt}}\left(\begin{array}{c}
\mathrm{i}_{\mathrm{L}} \\
\mathrm{V}_{\mathrm{pv}} \\
\mathrm{i}_{\mathrm{a}} \\
\mathrm{V}_{\mathrm{a}} \\
\omega
\end{array}\right)=\left(\begin{array}{ccccc}
-\frac{\mathrm{R}_{\mathrm{L}}}{\mathrm{L}} & \frac{1}{\mathrm{~L}} & 0 & -\frac{1}{\mathrm{~L}} & 0 \\
-\frac{1}{\mathrm{C}_{1}} & 0 & 0 & 0 & 0 \\
0 & 0 & -\frac{\mathrm{R}_{\mathrm{a}}}{\mathrm{L}_{\mathrm{a}}} & \frac{1}{\mathrm{~L}_{\mathrm{a}}} & -\frac{\mathrm{k}}{\mathrm{L}_{\mathrm{a}}} \\
\frac{1}{\mathrm{C}_{2}} & 0 & -\frac{1}{\mathrm{C}_{2}} & 0 & 0 \\
0 & 0 & \frac{\mathrm{k}}{\mathrm{j}} & 0 & -\frac{\mathrm{k}_{2}}{\mathrm{j}}
\end{array}\right)\left(\begin{array}{c}
\mathrm{i}_{\mathrm{L}} \\
\mathrm{V}_{\mathrm{pv}} \\
\mathrm{i}_{\mathrm{a}} \\
\mathrm{V}_{\mathrm{a}} \\
\omega
\end{array}\right)+\left(\begin{array}{c}
\frac{-\mathrm{R}_{\mathrm{m}} \mathrm{i}_{\mathrm{L}}+\mathrm{V}_{\mathrm{f} \omega}+\mathrm{V}_{\mathrm{a}}}{\mathrm{L}} \\
0 \\
0 \\
-\frac{\mathrm{i}_{\mathrm{L}}}{\mathrm{C}_{2}} \\
0
\end{array}\right) u+\left(\begin{array}{c}
-\frac{\mathrm{V}_{\mathrm{f \omega}}}{\mathrm{L}} \\
\mathrm{i}_{\mathrm{pv}} \\
\mathrm{C}_{1} \\
0 \\
0 \\
-\frac{\mathrm{k}_{1}}{\mathrm{j}}
\end{array}\right)
$$


The system can be represented as:

$\dot{\mathrm{x}}=\mathrm{A} \cdot \mathrm{x}+\mathrm{b}(\mathrm{x}) \mathrm{u}+\mathrm{d}$

Where :

$$
\mathrm{x}=\left(\begin{array}{c}
\mathrm{i}_{\mathrm{L}} \\
\mathrm{V}_{\mathrm{pv}} \\
\mathrm{i}_{\mathrm{a}} \\
\mathrm{V}_{\mathrm{a}} \\
\omega
\end{array}\right) \quad A=\left(\begin{array}{ccccc}
-\frac{\mathrm{R}_{\mathrm{L}}}{\mathrm{L}} & \frac{1}{\mathrm{~L}} & 0 & -\frac{1}{\mathrm{~L}} & 0 \\
-\frac{1}{\mathrm{C}_{1}} & 0 & 0 & 0 & 0 \\
0 & 0 & -\frac{\mathrm{R}_{\mathrm{a}}}{\mathrm{L}_{\mathrm{a}}} & \frac{1}{\mathrm{~L}_{\mathrm{a}}} & -\frac{\mathrm{k}}{\mathrm{L}_{\mathrm{a}}} \\
\frac{1}{\mathrm{C}_{2}} & 0 & -\frac{1}{\mathrm{C}_{2}} & 0 & 0 \\
0 & 0 & \frac{\mathrm{k}}{\mathrm{j}} & 0 & -\frac{\mathrm{k}_{2}}{\mathrm{j}}
\end{array}\right) \quad b(x)=\left(\begin{array}{c}
\frac{-\mathrm{R}_{\mathrm{m}} \mathrm{i}_{\mathrm{L}}+\mathrm{V}_{\mathrm{f \omega}}+\mathrm{V}_{\mathrm{a}}}{\mathrm{L}} \\
0 \\
0 \\
-\frac{\mathrm{i}_{\mathrm{L}}}{\mathrm{C}_{2}} \\
0
\end{array}\right) \mathrm{d}=\left(\begin{array}{c}
-\frac{\mathrm{V}_{\mathrm{f}_{\omega}}}{\mathrm{L}} \\
\frac{\mathrm{i}_{\mathrm{pv}}}{\mathrm{C}_{1}} \\
0 \\
0 \\
-\frac{\mathrm{k}_{1}}{\mathrm{j}}
\end{array}\right)
$$

\section{MPPT METHODS}

\subsection{P\&O}

To validate our proposed MPPT controller we have chosen to compare it to the P\&O method due to the fact that it is well known and communly used in the industry.

The operating principle of this algorithm is shown in Figure 2, and can be explained as follows: the voltage of the PV panel is disturbed then we calculate the power provided by the PV panel at time $\mathrm{k}$, and then it is compared to the previous one of the moment $(\mathrm{k}-1)$. If the difference is positive that is the power increases, it means that we are approaching MPP and the variation of the duty cycle is maintained in the same direction. On the other hand, if the difference is negative that is the power decreases, we are moving away from the MPP. So, we have to reverse the direction of the change in the duty cycle.

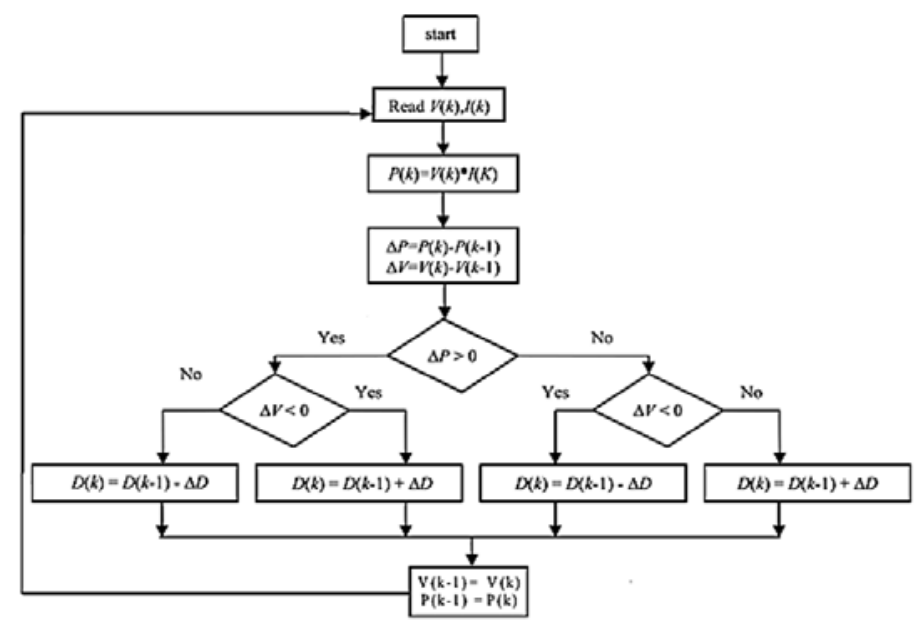

Figure 2. P\&O flowchart

\subsection{Sliding mode control}

Sliding Mode Control is a nonlinear controller based on the variable structure control (VSC). The advantages of the SMC are various: High precision, good stability, simplicity, invariance, robustness.

The design of the control is based on two important steps; first, the choice of the sliding surface $\mathrm{s}(\mathrm{x})$ $=0$ which determines the trajectory that the control should follow, second, determine the control laws that help maintain and stabilize this control on the sliding surface [5],[6]:

- The choice of the sliding surface:

The MPP is determined when :

Int J Pow Elec \& Dri Syst, Vol. 10, No. 1, March 2019 : $414-422$ 


$$
\frac{\partial \mathrm{P}_{\mathrm{pv}}}{\partial \mathrm{V}_{\mathrm{pv}}}=0
$$

Therefore, the sliding surface is defined as:

$$
\mathrm{S}=\frac{\partial \mathrm{P}_{\mathrm{pv}}}{\partial \mathrm{V}_{\mathrm{pv}}}=\frac{\partial \mathrm{I}_{\mathrm{pv}}^{2} \mathrm{R} p \mathrm{pv}}{\partial \mathrm{V}_{\mathrm{pv}}}=\mathrm{I}_{\mathrm{pv}}+\mathrm{V}_{\mathrm{pv}} \frac{\partial \mathrm{I}_{\mathrm{pv}}}{\partial \mathrm{V}_{\mathrm{pv}}}=0
$$

- The determination of the control law:

The control law consists of two parts: the first one called the equivalent control, it helps maintains the operation point in the sliding surface, the second one is the switching control and provides the stabilization of the controller [7], [8]:

$$
u=u_{\mathrm{eq}}+u_{\mathrm{n}}
$$

The equivalent control was first suggested by Slotine and $\mathrm{Li}$ [9] and is determined by the following condition:

$$
\dot{\mathrm{s}}=\left[\frac{\partial \mathrm{s}}{\partial \mathrm{x}}\right]^{\mathrm{T}} \dot{\mathrm{x}}=\left[\frac{\partial \mathrm{s}}{\partial \mathrm{x}}\right]^{\mathrm{T}}(\mathrm{A} \cdot \mathrm{x}+\mathrm{b}(\mathrm{x}) \mathrm{u}+\mathrm{d})=0
$$

We consider $\mathrm{d}=0$, to simplify the calculations, the equivalent control becomes:

$$
u_{\mathrm{eq}}=-\frac{\left[\frac{\partial \mathrm{s}}{\partial \mathrm{x}}\right]^{\mathrm{T}}(\mathrm{A} \cdot \mathrm{x})}{\left[\frac{\partial \mathrm{s}}{\partial \mathrm{x}}\right]^{\mathrm{T}} \mathrm{b}(\mathrm{x})}
$$

The switching control can be a linear function of the sliding surface, it is given by:

$$
u_{\mathrm{n}}=-\mathrm{k}_{\mathrm{s}} \cdot \operatorname{sgn}(\mathrm{s})
$$

ks is a positive constant determined by the constructer.

Thus the SMC controller is:

$$
u=-\frac{\left[\frac{\partial s}{\partial x}\right]^{T}(A \cdot x)}{\left[\frac{\partial s}{\partial x}\right]^{T} b(x)}-k_{s} \cdot \operatorname{sgn}(s)
$$

Stabilization study:

We chose to use a function named Lyapunov given by:

$$
V=\frac{1}{2} s^{2}
$$

The derivative of this function is:

$$
\dot{\mathrm{V}}=\mathrm{s} \dot{\mathrm{s}}<0 \forall \mathrm{s} \neq 0
$$

\subsection{Adaptive fuzzy sliding mode control}

Despite the robustness of the sliding mode control, it causes drawbacks. The main disadvantage is the chattering phenomenon caused by the high oscillations around the sliding surface. In addition, to achieve a fast convergence and more stability, it is recommended to use high values of switching gain. However, the higher the gain the more oscillations there are.

Adaptive fuzzy sliding mode based MPPT controller for a photovoltaic water pumping system (Sabah Miqoi) 
Figure 3(a) represents the output power using the sliding mode controller for different solar irradiation levels of 800, 1000 and 600 and a fixed temperature. We can see that the more we increase the gain, the more there is oscillations, and the higher the power production.

On the other hand, if we consider Figure 3(b) which represents the output power for a one-day see Figure 9, we can see that if we increase the gain the robustness of the controller increases as well as the oscillations which makes the controller unstable. For a small gain of 0.5 despite its stability it is less robust and produces less energy compared to other gain.
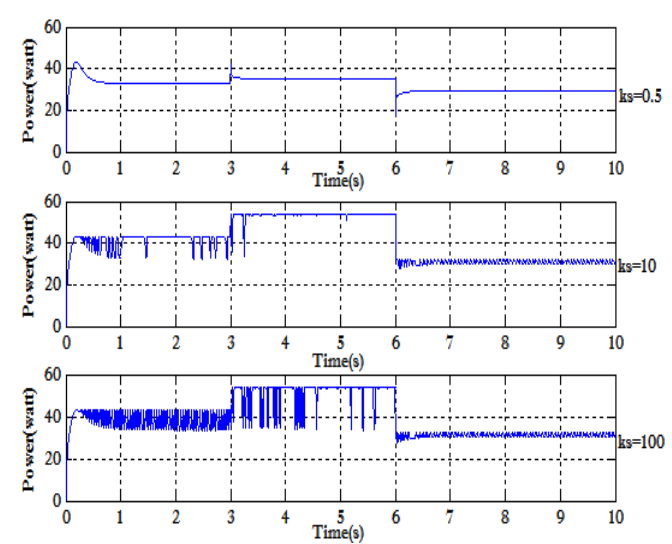

(a)
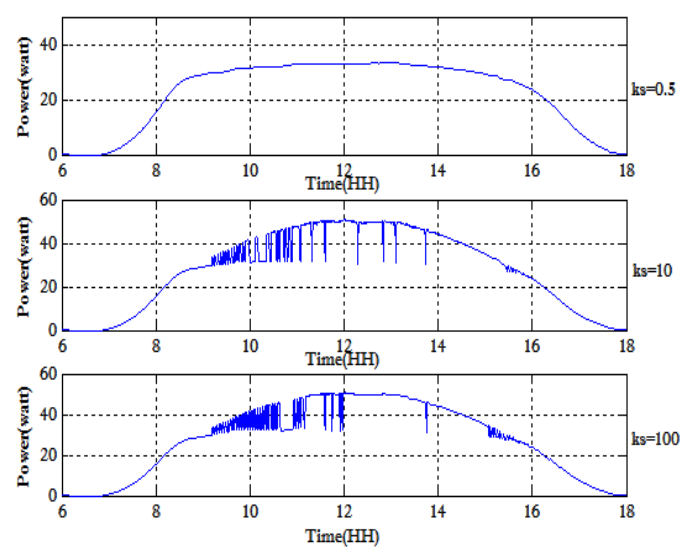

(b)

Figure 3. Comparison of output power for different gain

So, to find a balance between the stability and the robustness we opted to use an adaptive gain, since a constant-gain feedback controller is not able to properly track the MPP due to the constant change of the weather. Figure 4 show the adaptive fuzzy control.

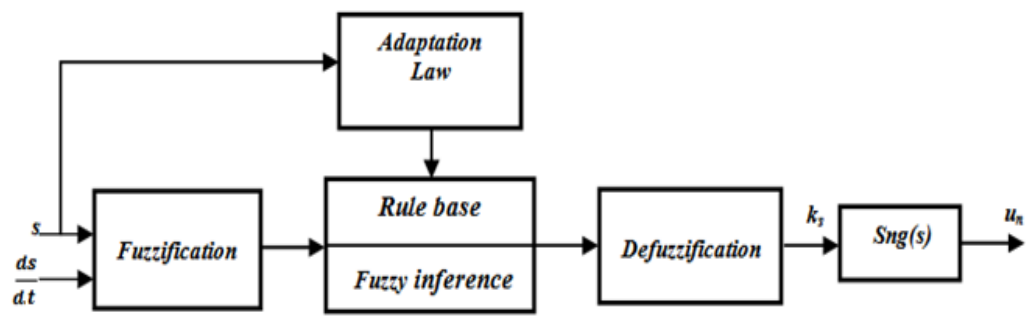

Figure 4. the adaptive fuzzy control

This controller combines the sliding mode concept with fuzzy control strategy to design an adaptive fuzzy sliding mode controller, the adaptive fuzzy will serve to generate adaptive switching gain. As we established in (7), the control law consists of two controls an equivalent control that we are not changing, and a switching control that contains the modified gain.

As shown on the Figure 5 the input signals of the fuzzy logic control are the sliding surface $s$ and its derivative ds/dt, the output of is the switching gain ks. The fuzzy rules are given in the following form [9]:

Rule $\mathrm{j}$ : IF $s$ is $A_{\mathrm{j}}^{\mathrm{i}}$ and $\dot{s}$ is $A_{\mathrm{j}}^{\mathrm{i}}$; THEN ks is $B_{\mathrm{j}}^{\mathrm{i}}$

$A_{j}^{i}$ and $B_{j}^{i}$ are respectively the input and output fuzzy sets. By using the centre average defuzzification method, the output value of the fuzzy system is as follow: 
$k_{s}=\frac{\sum_{j} y_{j}\left(\prod_{i=1}^{n} \mu A_{j}^{i}\right)}{\sum_{j} \prod_{i=1}^{n} \mu A_{j}^{i}}$

Where $\mu A_{j}^{i}$ the membership is function value of a linguistic variable and $y_{j}$ define a crisp value at which the output membership function $\mu B_{j}^{i}$ achieves its maximum $\mu B_{j}^{i}=1$.

The (24) can be expressed as follow:

$$
k_{s}=y^{T} \xi
$$

Where $y$ is an adjustable parameter vector, $\xi$ is a fuzzy basis function vector, and $\xi_{j}=\frac{\prod_{i=1}^{n} \mu A_{j}^{i}}{\sum_{j} \prod_{i=1}^{n} \mu A_{j}^{i}}$ $\mathrm{j}=1,2,3 \ldots \mathrm{m}$.

Applying an adaptive control we get the following equation:

$$
\hat{k}_{s}=\hat{y}^{T} \xi
$$

According to the universal approximation theorem [10], there exists an optimal parameter y that satisfies:

$$
k_{s}^{*}=y^{* T} \xi+\varepsilon
$$

Where $\hat{y}$ is the estimation of $\mathrm{y}^{*}$, and $\varepsilon$ is the approximation error delimited by $|\varepsilon|<\mathrm{E}$, E is a positive constant.

Stabilization study:

The Lyapunov function is defined as following [10]:

$V=\frac{1}{2} s^{2}+\frac{1}{2} \gamma \tilde{y}^{T} \dot{y}$

Where $\tilde{y}=y^{*}-\hat{y}$ and $\gamma$ is a positive constant.

$$
\tilde{k}_{s}=k_{s}^{*}-\hat{k}_{s}=y^{* T} \xi+\varepsilon-\hat{y} \quad \xi=\tilde{y}^{T} \xi+\varepsilon
$$

To ensure that the controller is stable the derivative of Lyapunov function must be lower than zero:

$$
\begin{aligned}
& \dot{V}=s \dot{s}+\gamma \dot{y} \dot{y} \\
& \dot{s}=\left[\frac{\partial s}{\partial x}\right]^{T}(A x+b(x) u+d)=\left[\frac{\partial s}{\partial x}\right]^{T}\left(A x+b(x)\left[\mathrm{u}_{\mathrm{eq}}-\mathrm{k}_{\mathrm{s}} \operatorname{sgn}(\mathrm{s})\right]+d\right) \\
& \dot{s}=\left[\frac{\partial s}{\partial x}\right]^{T}\left(A x+b(x) \mathrm{u}_{\mathrm{eq}}+d-b(x) \tilde{\mathrm{k}}_{\mathrm{s}} \operatorname{sgn}(\mathrm{s})\right) \\
& \text { Considering that } \dot{\mathrm{x}}_{\mathrm{eq}}=\mathrm{A} \cdot \mathrm{x}+\mathrm{b}(\mathrm{x}) \mathrm{u}_{\mathrm{eq}}+\mathrm{d}=0 \\
& \text { From } 31 \text { becomes: } \\
& \dot{s}=-\left[\frac{\partial s}{\partial x}\right]^{T} b(x) \tilde{\mathrm{k}_{\mathrm{s}}} \operatorname{sgn}(\mathrm{s})
\end{aligned}
$$


We apply to:

$\dot{V}=-s\left[\frac{\partial s}{\partial x}\right]^{T} b(x) \tilde{\mathrm{k}_{\mathrm{s}}} \operatorname{sgn}(\mathrm{s})+\gamma \dot{y} \dot{y}=-s\left[\frac{\partial s}{\partial x}\right]^{T} b(x)(\dot{y} \xi+\varepsilon) \operatorname{sgn}(\mathrm{s})+\gamma \dot{y} \dot{y}$

$\dot{V}=-\tilde{y}^{T}\left[\left[\frac{\partial s}{\partial x}\right]^{T}|s| b(x) \xi+\gamma \dot{\hat{y}}\right]-|s|\left[\frac{\partial s}{\partial x}\right]^{T} b(x) \varepsilon$

Let the adaptive rule be:

$\hat{y}=-\frac{1}{\gamma}\left[\frac{\partial s}{\partial x}\right]^{T}|s| b(x) \xi$

Then we will have:

$\dot{V}=-|s|\left[\frac{\partial s}{\partial x}\right]^{T} b(x) \varepsilon \leq-|s| \varepsilon \leq 0$

Due to fact that $\varepsilon$ is positive $\dot{V}$ is undeniably negative which proves the stability of the system.
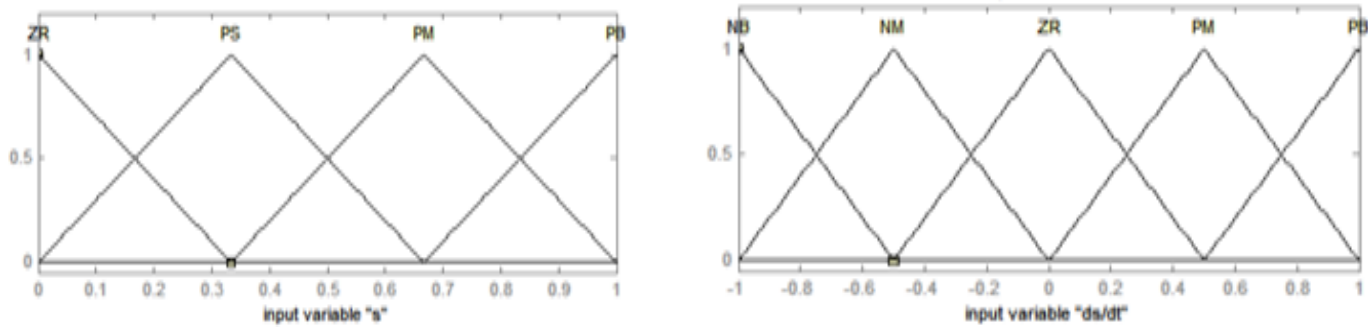

Figure 5. Input fuzzy memberships

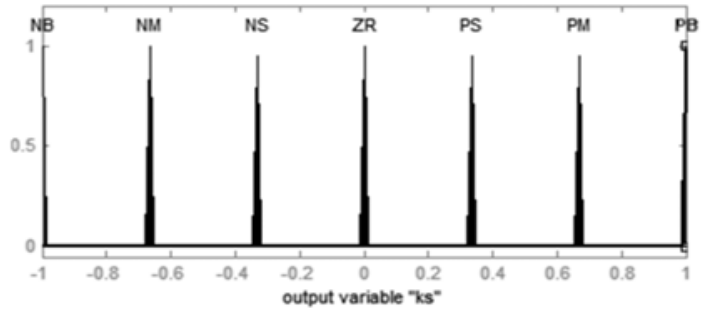

Figure 6. Output fuzzy memberships

The fuzzy rules are summarized in the Table 1. And membership functions for the input $S$ and $\dot{S}$ are represented in Figure 6. For the output of the fuzzy system ks seven equidistantly placed singletons are used, as shown in Figure 7. The membership functions are categorized by linguistic values Negative Big (NB), Negative Medium (NM), Negative Small (NS), Zero (ZR), Positive Small (PS), Positive Medium (PM) and Positive Big (PB).

Table 1. Fuzzy rules

\begin{tabular}{llllll}
\hline $\mathbf{s} \backslash \dot{\mathbf{s}}$ & $\mathrm{NB}$ & $\mathrm{NM}$ & $\mathrm{ZR}$ & $\mathrm{PM}$ & $\mathrm{PB}$ \\
\hline $\mathrm{ZR}$ & $\mathrm{PM}$ & $\mathrm{PS}$ & $\mathrm{ZR}$ & $\mathrm{NS}$ & $\mathrm{NM}$ \\
$\mathrm{PS}$ & $\mathrm{PS}$ & ZR & NS & NM & NB \\
PM & ZR & NS & NS & NM & NB \\
PB & ZR & NS & NM & NB & NB \\
\hline
\end{tabular}

Int J Pow Elec \& Dri Syst, Vol. 10, No. 1, March 2019: 414-422 


\section{RESULTS}

The PV water pumping system has been modelled and simulated using MATLAB/SIMULINK and the proposed controlled AFSMC was compared to both the Sliding mode control and the P\&O algorithm to see its benefits in extracting the maximum power and also to validate the functionality of this controller. Table 2 represents the parameters of the PV water pumping system:

Table 2. System parameters

\begin{tabular}{lll}
\hline PV panel TE500CR & Boost converter & DC motor \\
\hline Wmpp $=55$ watts & $\mathrm{R}_{\mathrm{L}}=0.5 \Omega$ & $\mathrm{R}_{\mathrm{a}}=1.254 \Omega$ \\
Vmpp=17,50V & $\mathrm{L}=6.810^{-3} \mathrm{H}$ & $\mathrm{L}_{\mathrm{a}}=2810^{-3} \mathrm{H}$ \\
Impp $=3,10 \mathrm{~A}$ & $\mathrm{C}_{1}=6.210^{-3} \mathrm{~F}$ & $\mathrm{k}_{1}=0.1 \mathrm{~kg} \cdot \mathrm{m}^{2} \cdot \mathrm{rad} / \mathrm{sec}$ \\
Voc $=21,7 \mathrm{~V}$ & $\mathrm{C}_{2}=2.8810^{-3} \mathrm{~F}$ & $\mathrm{k}_{2}=0.0114 \mathrm{~kg} \cdot \mathrm{m}^{2} / \mathrm{sec}^{2}$ \\
$\mathrm{Isc}=3,5 \mathrm{~A}$ & & $\mathrm{j}=0.004 \mathrm{~kg} \cdot \mathrm{m}^{2}$ \\
$\mathrm{Ns}=36$ & & $\mathrm{k}=0.333 \mathrm{~V} \cdot \mathrm{sec} / \mathrm{rad}$ \\
\hline
\end{tabular}

Firstly we made the comparison for a fixed temperature of $25^{\circ} \mathrm{C}$ and variable solar irradiations, as shown in Figure 7,in order to see closely the deference and the advantage of adding the fuzzy adaptive to the $\mathrm{SMC}$, we have extracted the power for three different value of the solar irradiation, Figure 8 shows the variation of the output panel power.

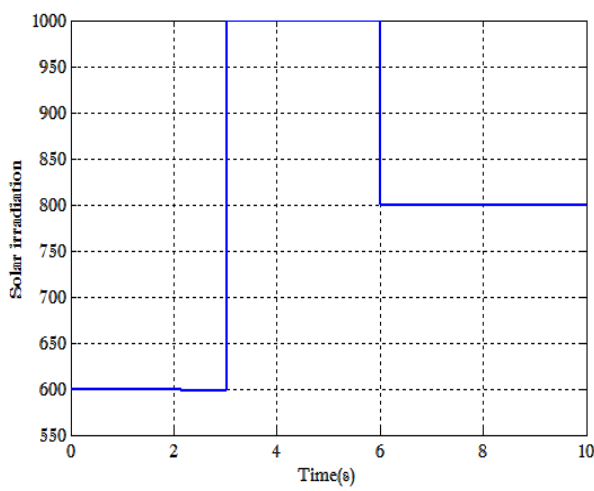

Figure 7. Solar irradiation

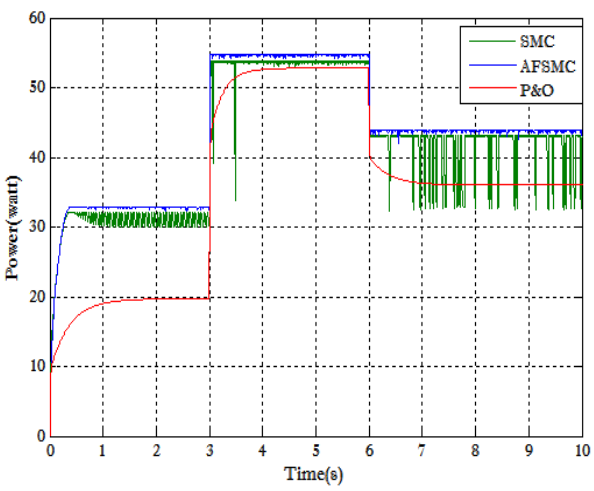

Figure 8. Power variation for fixed temperature and variable irradiation

According to the Figure 8, we can see that the proposed method AFSMC is better than the other two methods. Compared to the P\&O the SMC and AFSMC are way better and produce more power. If we compare the SMC and AFSMC, we note that the AFSMC is slightly higher than the SMC an there are fewer oscillations and we can conclude that our proposed method is more efficient. Afterward, we made the comparison of the three methods using the weather data for a one specific day, Figure 9 shows the data of temperature and irradiation sequentially for this day.
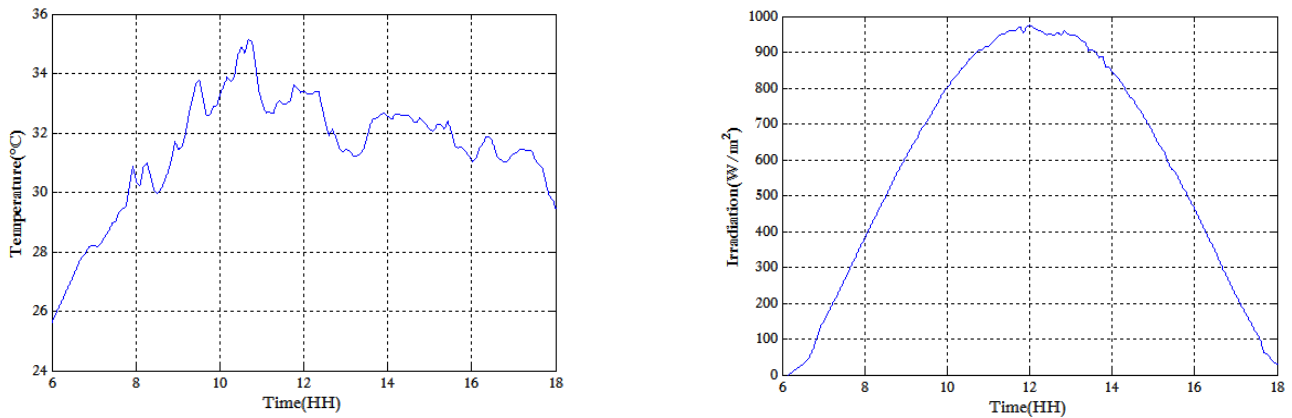

Figure 9. Solar irradiation data for a day 
We have extracted the variation of the output power for those solar irradiations and temperature data, as it is shown in Figure 10. We also extracted the Motor DC speed see Figure 11. And we can see that AFSMC has less oscillation and there is no deviation of the curve, like the one we can see on the SMC curve.

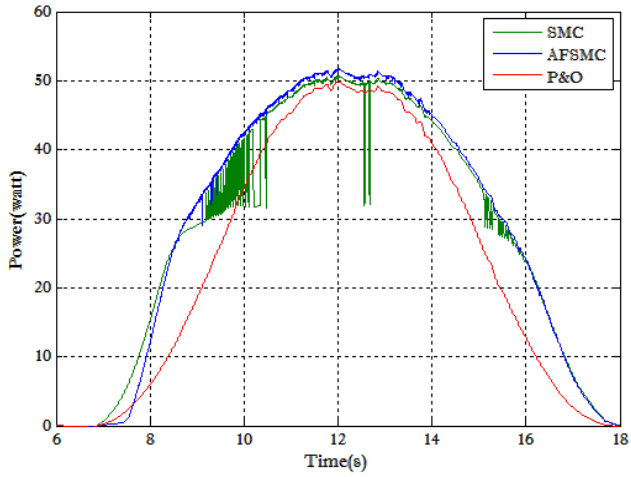

Figure 10. PV power variation

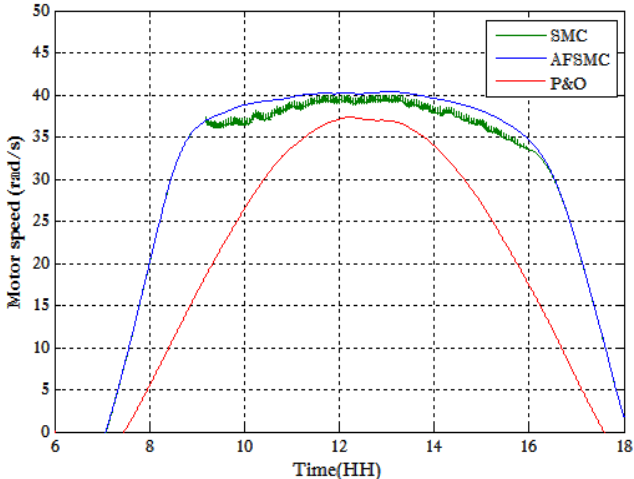

Figure 11. Motor DC speed variation

All those results show clearly the superiority and efficiency of the proposed controller AFSMC compared to the SMC and the P\&O. furthermore there are fewer oscillations on the proposed controller curve which prove its stability and good performance.

\section{CONCLUSION:}

In this work we did the study of a photovoltaic water pumping system then we modelized and simulated this system using MATLAB/SIMULINK simulator, next we have developed a new maximum power point tracker called AFSMC adaptive fuzzy sliding mode controller, this controller is based on the robust method sliding mode. We have added to this last the adaptive fuzzy method in order to ameliorate the performance of the SMC and to overcome the chattering phenomena. We have compared this method to the $\mathrm{SMC}$ and the $\mathrm{P} \& \mathrm{O}$ in order to validate this controller. The extracted results whether of the power shows the robustness and efficiency of this method. In future work, we hope to be able to apply this method in reality and confirm the efficiency of this controller.

\section{REFERENCES}

[1] Abdourraziq S, Abdourraziq MA, and Darab C, "Photovoltaic water pumping system application in Morocco," In Electromechanical and Power Systems (SIELMEN)," 2017 International Conference on Oct 11, pp. 271-274. IEEE, 2017.

[2] Dolara A, Faranda R, and Leva S, "Energy comparison of seven MPPT techniques for PV systems," Journal of Electromagnetic Analysis and Applications, Sep 28; 1(03):152, 2009.

[3] Rao DV and Go TH, "Automatic landing system design using sliding mode control," Aerospace Science and Technology, Jan 1; 32(1):180-7, 2014.

[4] Bellia H, Youcef R, and Fatima M, "A detailed modeling of photovoltaic module using MATLAB," NRIAG Journal of Astronomy and Geophysics, Jun 1; 3(1):53-61, 2014.

[5] Utkin VI, "Sliding mode control design principles and applications to electric drives," IEEE transactions on industrial electronics. Feb; 40(1):23-36, 1993.

[6] Slotine JJ and Li W, "Applied nonlinear control. Englewood Cliffs,” NJ: Prentice hall; 1991 Jan.

[7] Rekioua D, Achour AY, and Rekioua T, "Tracking power photovoltaic system with sliding mode control strategy," Energy Procedia, Jan 1; 36:219-30, 2013.

[8] Anusuyadevi R, Pandiarajan S, and Bharathi J.M, "Maximum Power Point Tracking of DC To DC Boost Converter Using Sliding Mode Control," International Journal of Power Electronics and Drive Systems (IJPEDS), Jan 1;3(3):321-7, 2013.

[9] Cerman $\mathrm{O}$ and Hušek P, "Adaptive fuzzy sliding mode control for electro-hydraulic servo mechanism," Expert Systems with Applications, Sep 1;39(11):10269-77, 2012

[10] Soltanpour M.R, Khooban M.H, and Khalghani M.R, "An optimal and intelligent control strategy for a class of nonlinear systems: adaptive fuzzy sliding mode," Journal of Vibration and Control, Jan; 22(1):159-75, 2016.

Int J Pow Elec \& Dri Syst, Vol. 10, No. 1, March 2019 : $414-422$ 